\title{
PENGARUH SAFETY CLIMATE TERHADAP KECELAKAAN KERJA DENGAN SAFETY BEHAVIOR SEBAGAI VARIABEL INTERVENING PADA KARYAWAN PT. PANCA WANA INDONESIA DI KRIAN
}

\author{
Mohammad Agus Setiawan \\ Tri Siwi Agustina \\ Departemen Manajemen Fakultas Ekonomi dan Bisnis Universitas Airlangga
}

ABSTRACT

This study aims to analyze the effect of safety climate on job accident at employees of PT. Panca Wana Indonesia with safety behavior as intervening variable. The research was conducted on supervisor and employees at operational and production department with a sample of 87 persons. The analysis technique used is a path analysis. The independent variable in this research is the safety climate $(X)$, is the intervening variable safety behavior $(Z)$, and the dependent variable is job accident (Y). Results of this study indicate that safety climate has direct effect and significant on job accident is proved, because it has a significance value (Sig) t 0,000 less than the significance level (a) of $5 \%$ t, and safety climate is proved has a effect on job accident with safety behavior as intervening variable, because the value of significance (Sig) † variable safety climate to safety behavior, and safety behavior to job accident are 0,000 , is smaller than the value significance level (a) by $5 \%$.

Keywords : Safey Climate, Safety Behavior, Job Accident.

\section{PENDAHULUAN}

Kajian tentang safety climate (iklim keselamatan kerja) telah sejak lama memiliki daya tarik tersendiri bagi kalangan pendidik, manajer, dan peneliti, terutama dikaitkan dengan tingkat kecelakaan di suatu perusahaan. Berdasarkan beberapa penelitian, menjelaskan bahwa kecelakaan kerja banyak terjadi akibat kondisi lingkungan kerja yang tidak aman.

Data Kementerian Tenaga Kerja dan Transmigrasi menyebutkan, sampai tahun 2013 di Indonesia tidak kurang dari enam pekerja meninggal dunia setiap hari akibat kecelakaan kerja. Angka tersebut tergolong tinggi dibandingkan negara Eropa yang hanya sebanyak dua orang meninggal per hari karena kecelakaan kerja. Sementara menurut data International Labor Organization (ILO), di Indonesia rata-rata per tahun terdapat 99.000 kasus kecelakaan kerja. Dari total jumlah itu, sekitar 70 persen berakibat fatal yaitu kematian dan cacat seumur hidup.

Tingkat statistik menurut data Kementerian Tenaga Kerja dan Transmigrasi tahun 2013 menunjukkan bahwa kecelakaan kerja sebagian besar terjadi pada perusahaan 


\section{Mohammad Agus Setiawan \\ Tri Siwi Agustina}

manufaktur dibandingkan pada perusahaan jasa, hal ini didukung dengan adanya alat-alat operasional dan mesin-mesin produksi sehingga membutuhkan keahlian dan teknik khusus untuk mengoperasikannya. Terlebih beberapa instruksi dan aktivitas kerja membutuhkan tenaga dan fokus yang tinggi, sehingga seringkali terjadi kecelakaan kerja yang disebabkan kesalahan operasional dan kurangnya fokus karyawan.

Dalam wawancara yang dilakukan peneliti dengan kepala bagian maintenance PT. Panca Wana Indonesia pada bulan September 2014 menjelaskan bahwa dalam periode Mei 2013 sampai dengan Juni 2014 terdapat total 144 kasus dimana 100 kasus kecelakaan tersebut membutuhkan perawatan lebih lanjut sehingga harus dibawa ke rumah sakit terdekat. Hal ini diakibatkan oleh perilaku dari karyawan yang kurang memperhatikan kondisi dan kelengkapan alat keamanan saat beraktivitas di perusahaan. Selain itu, kecelakaan tersebut tidak hanya diakibatkan oleh perilaku dari para karyawannya, namun dalam beberapa kasus kecelakaan ada yang terjadi pada saat pengoperasian mesinmesin produksi, hal ini diakibatkan oleh jenis mesin produksi yang dimiliki perusahaan sebagian besar merupakan mesin-mesin buatan luar negeri, sehingga membutuhkan keahlian khusus dan training lebih lanjut dalam pengoperasian mesin tersebut, namun dalam kenyataannya masih banyak karyawan yang belum atau kurang mendapatkan arahan lebih lanjut dalam pengoperasian mesin produksi tersebut.

Berdasarkan latar belakang masalah, maka dapat diambil rumusan masalah sebagai berikut: (1.) Apakah safety climate mempunyai pengaruh langsung yang signifikan terhadap kecelakaan kerja pada karyawan PT. Panca Wana Indonesia? (2.) Apakah safety climate mempunyai pengaruh tidak langsung yang signifikan terhadap kecelakaan kerja melalui safety behavior sebagai variabel intervening pada karyawan PT. Panca Wana Indonesia?, Sesuai dengan rumusan masalah di atas maka penelitian ini bertujuan: (1.) Untuk mengetahui apakah terdapat pengaruh langsung yang signifikan dari safety climate terhadap kecelakaan kerja pada karyawan PT. Panca Wana Indonesia. (2.) Untuk mengetahui apakah terdapat pengaruh tidak langsung yang signifikan antara safety climate dengan kecelakaan kerja dengan safety behavior sebagai variabel intervening pada karyawan PT. Panca Wana Indonesia.

\section{LANDASAN TEORI}

\section{Safety Climate}

Zohar dalam Clarke (2006) mendefinisikan safety climate sebagai kesimpulan atau hasil akhir dari persepsi yang pekerja terkait dengan lingkungan kerjanya dan merupakan batasan dari aturan untuk mengarahkan pekerja pada perilaku yang tepat dan mengubah perilaku pekerja atas tugasnya, serta upaya individu dalam memberi arti dan interpretasi pada lingkungan kerjanya. 


\section{Jurnal Manajemen Teori dan Terapan \\ Tahun 7. No. 2, Agustus 2014}

Cooper et al., (2004) menjabarkan bahwa safety climate sebagai suatu gambaran yang dirasakan atau terkait dengan persepsi pekerja akan pentingnya keselamatan dan bagaimana hal tersebut bisa ditetapkan dalam organisasi. Oleh karena itu, safety climate berhubungan dengan persepsi mengenai kebijakan, prosedur, dan praktek keselamatan kerja. Hal ini sesuai dengan definisi safety climate menurut Neal dan Griffin (2002), yaitu persepsi karyawan atas kebijakan, prosedur, dan praktek yang terkait dengan keselamatan kerja. Safety climate dijelaskan oleh Flin et al., (2004) sebagai gambaran pekerja mengenai keadaan iklim kesehatan dan keselamatan kerja yang merupakan indikator dari budaya keselamatan kerja pada suatu kelompok atau organisasi.

Dukungan manajemen terhadap keselamatan dan kepentingan keselamatan dalam perusahaan adalah kunci keberhasilan safety climate (Flin et al. dalam Dejoy et al. 2004). Safety climate terhubung dengan berbagai macam faktor terkait dengan keselamatan, termasuk performa atas perilaku aman yang nyata aktifitas yang terkait dengan keselamatan atau keefektifan program keselamatan dalam perusahaan, interpretasi terhadap kecelakaan dan berbagai kejadian lain seperti kecelakaan atau insiden lain yang terkait dengan keselamatan dalam perusahaan (Griffin dan Neal, 2000; Zohar dalam Dejoy et al., 2004).

Cooper dan Phillips dalam Clarke (2006) mengindikasikan bahwa pekerja yang menerima beban kerja yang lebih berat punya persepsi yang buruk (safety climate negatif). Sedangkan menurut Clarke (2006) yang mempengaruhi atau menghambat safety climate pekerja adalah: lingkungan kerja, komunikasi ditempat kerja, dan beberapa aspek demografis seperti: usia, jenis kelamin, jabatan, dan pekerjaan itu sendiri.

\section{Safety Behavior}

Perilaku keselamatan (Safety behavior) menurut APA dictionary of psychology (2007) adalah suatu perilaku yang dilakukan dengan keterkaitan individu dalam usaha untuk memperkecil atau mencegah suatu bencana yang dilakukan.

Bird dan Germain (1990) menjelaskan bahwa perilaku keselamatan (safety behavior) adalah perilaku yang tidak dapat menyebabkan terjadinya kecelakaan atau insiden. Perbedaan perilaku keselamatan dan perilakU K3 (kesehatan dan keselamatan kerja) yaitu perilaku keselamatan hanya berfokus kepada keselamatannya, sedangkan perilaku K3 tidak hanya pada keselamatan namun juga pada kesehatan kerjanya.

Menurut Neal dan Griffin (2004) ada dua faktor yang mempengaruhi perilaku keselamatan (Safety behavior), yaitu: (1.) Faktor-faktor yang berasal dari dalam individu, seperti komitmen, perbedaan individu misalnya ketelitian, kepribadian contohnya karakter 


\section{Mohammad Agus Setiawan \\ Tri Siwi Agustina}

yang dimiliki bersifat permanen atau orang tersebut memiliki kecenderungan untuk mengambil tindakan aman. (2.) Lingkungan kerja, seperti iklim keselamatan dan faktor organisasional misalnya supervisi dan desain pekerjaan.

\section{Kecelakaan Kerja}

Menurut Hinze (1997) yang dimaksudkan dengan kecelakaan kerja adalah kejadian yang tidak disengaja seperti kejadian-kejadian yang tidak diharapkan dan tidak terkontrol. Kecelakaan tidak selalu berakhir dengan luka fisik dan kematian. Kecelakaan yang menyebabkan kerusakan peralatan dan material dan khususnya yang menyebabkan luka perlu mendapat perhatian besar. Semua kecelakaan tanpa melihat apa itu menyebabkan kerusakan ataupun tidak perlu mendapat perhatian besar. Kecelakaan kerja yang tidak menyebabkan kerusakan peralatan, material dan kecelakaan fisik dari personil kerja dapat menyebabkan kecelakaan lebih lanjut. Sementara itu, Occupational Safety and Health Administration (OSHA) menjelaskan bahwa kecelakaan kerja yang dicatat merupakan kecelakaan yang dimana minimal membutuhkan lebih dari pertolongan pertama.

Dalam teori domino Heinrich (1980), kecelakaan terdiri atas lima faktor yang saling berhubungan yaitu kondisi kerja, kelalaian manusia, tindakan tidak aman, kecelakaan dan cedera. Heinrich (1980) berpendapat bahwa kecelakaan pada pekerja terjadi sebagai rangkaian yang saling berkaitan. Kelima faktor ini tersusun layaknya kartu domino yang diberdirikan. Jika satu kartu jatuh, maka kartu ini akan menimpa kartu lain hingga kelimanya akan roboh secara bersama. Menurut Heinrich (1980), kunci untuk mencegah kecelakaan adalah dengan menghilangkan tindakan tidak aman sebagai poin ketiga dari kelima faktor. Menurut penelitian yang dilakukannya tindakan tidak aman menyumbang $98 \%$ penyebab kecelakaan, selain itu untuk mencegah terjadinya kecelakaan, kuncinya adalah dengan memutuskan rangkaian sebab-akibat.

Menurut penelitian Copper et al. (2004), iklim keselamatan kerja mengacu pada sejauh mana persepsi karyawan terhadap kinerja keselamatan yang diberikan organisasi, dan diukur untuk memberikan sistem peringatan keselamatan yang berpotensi untuk terjadinya kecelakaan. Namun, para peneliti telah berjuang selama terakhir 25 tahun untuk menemukan bukti empiris menunjukkan hubungan yang sebenarnya antara iklim keselamatan dan perilaku keselamatan. Metode yang digunakan adalah dengan mengukur safety climate yang berupa kuisioner yang dibagikan kepada karyawan pada beberapa perusahaan manufaktur. Awalnya sebuah inisiatif safety behavior dibuat dan didistribusikan selama periode satu tahun. Hasilnya berupa analisis regresi yang menunjukkan bahwa persepsi tentang pentingnya pelatihan keselamatan kerja dapat memprediksi tingkat aktual safety behavior. Hasil penelitian juga menunjukkan bahwa besarnya nilai perubahan safety climate persepsi belum tentu cocok dengan perubahan aktual $(r=0,56)$ 
dalam safety behavior karyawan. Hasil diskusi menunjukan bahwa diperoleh hubungan empiris antara skor safety climate dan skor aktual safety behavior. Kesimpulannya adalah bahwa hubungan yang signifikan antara safety climate dengan safety behavior akan diperoleh jika data yang diperoleh tentang safety behavior cukup dikumpulkan.

Persamaan dari penelitian ini adalah memiliki kesamaan variabel yaitu safety climate, dan safety behavior. Sedangkan perbedaan penelitian ini dengan penelitian Cooper (2004) adalah tidak terdapat variabel kecelakaan kerja, sedangkan pada penelitian ini terdapat variabel tersebut. Disamping itu, pada penelitian ini menggunakan objek penelitian karyawan PT. Panca Wana Indonesia yang berbeda dengan penelitian Cooper (2006) yang menggunakan objek penelitian beberapa perusahaan manufaktur.

\section{Model Analisis}

Model Analisis yang digunakan dalam penelitian ini adalah :

H1

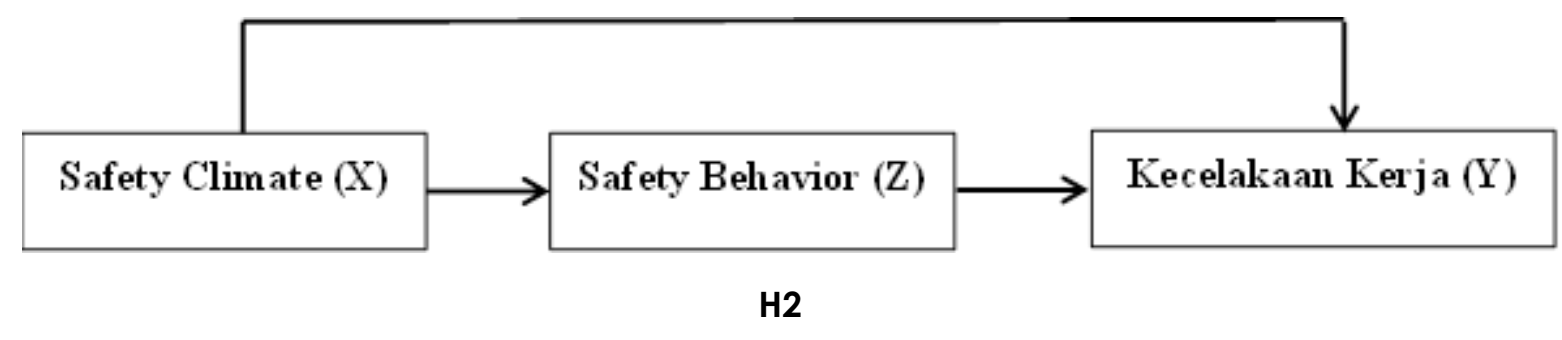

Gambar 1.1. Model Analisis

Berdasarkan rumusan masalah, tujuan penelitian, manfaat penelitian dan landasan teori yang telah diuraikan sebelumnya, maka model analisis dalam penelitian ini mempunyai hipotesis sebagai berikut :

$\mathrm{H} 1$ : Safety Climate mempunyai pengaruh signifikan terhadap Kecelakaan Kerja pada karyawan PT. Panca Wana Indonesia.

H2 : Safety Climate mempunyai pengaruh tidak langsung dan signifikan terhadap Kecelakaan kerja dengan Safety Behavior sebagai variabel intervening pada karyawan PT Indonesia.

\section{METODE PENELITIAN}

Pada penelitian ini menggunakan pendekatan metode penelitian kuantitatif. Metode penelitian kuantitatif merupakan penelitian yang lebih menekankan pada pengujian hipotesis untuk membuktikan suatu dugaan yang sesuai dengan tujuan yang ingin dicapai. Metode penelitian ini dimulai dengan hipotesis, teori-teori, kemudian membuat model analisis, identifikasi variabel, definisi variabel, mengumpulkan data (Primer dan Sekunder) dan selanjutnya melakukan analisis terhadap hasil penelitian. Dengan 


\section{Mohammad Agus Setiawan \\ Tri Siwi Agustina}

menggunakan data yang terukur, maka pada metode penelitian kuantitatif akan menghasilkan simpulan yang dapat digeneralisasikan.

Definisi operasional digunakan untuk mendefinisikan variabel-variabel yang telah dijelaskan sebelumnya agar variabel tersebut dapat dioperasionalkan. Definisi operasional masing-masing variabel dapat dijelaskan sebagai berikut:

Untuk variabel Safety Climate (X) sebagai variabel bebas merupakan persepsi pekerja atas kebijakan, prosedur, dan praktek yang terkait dengan keselamatan kerja. Dalam penelitian ini, peneliti menggunakan teori safety cliamte dari pendapat Glendon dan Litherland (2001) dimana terdapat tiga dimensi yang digunakan dimana dalam masingmasing faktor terdapat 4 indikator, dimensi tersebut adalah Communication and Support, Procedures, dan Work Pressures.

Safety Behavior (Z) sebagai variabel intervening merupakan perilaku karyawan yang tidak dapat menyebabkan terjadinya kecelakaan. Dalam penelitian ini, peneliti mengacu pada penelitian Martinez-corcoles et al., (2011), indikator yang digunakan untuk mengukur variabel safety behavior adalah seberapa sering karyawan menunjukkan perilaku-perilaku: (1.) Mengabaikan aturan keselamatan agar mencapai target pekerjaan, (2.) Melanggar prosedur kerja, (3.) Tidak menggunakan alat pelindung diri (Helm, sepatu boots, sarung tangan) dengan benar, (4.) Bercanda gurau dengan rekan kerja saat melakukan pekerjaan, (5.) Memperbaiki peralatan dengan kondisi alat masih menyala, (6.) Melanggar aturan karena tekanan dari manajemen.

Kecelakaan kerja (Y) didefinisikan sebagai suatu kejadian yang tidak direncanakan, tidak diinginkan, tidak diharapkan yang mengakibatkan luka, sakit, kerusakan, kerugian, dan lain-lain pada individu. Indikator kecelakaan kerja yang digunakan mengacu pada Hofmann dan Stetzer (1998) yang dikembangkan oleh peneliti, dimana dari indikatorindikator tersebut disimpulkan item pertanyaan untuk questionnaire untuk variabel kecelakaan kerja, item-item tersebut ditujukan untuk para supervisor. Indikator variabel kecelakaan kerja yaitu penilaian supervisor terhadap sebab dari terjadinya kecelakaan kerja karyawan tersebut antara lain: (1) Lingkungan kerja yang buruk, (2) Tindakan manajer dan supervisor yang kurang memperhatikan karyawan, (3.)Karyawan yang terlalu lelah, (4.) Kondisi stres karyawan, (5.) Kurangnya kesadaran karyawan akan keselamatan.

Untuk melakukan penilaian terhadap variabel safety climate $(X)$, variabel safety behavior (Z), dan variabel kecelakaan kerja (Y) digunakan skala Likert dengan menggunakan lima poin (1-5). Penjelasan ke lima skala Likert tersebut adalah sebagai berikut : Nilai 1 mewakili jawaban Sangat Tidak Setuju (STS) atau Sangat Sering (SS), Nilai 2 mewakili jawaban Tidak Setuju (TS) atau Sering (S), Nilai 3 mewakili jawaban Cukup Setuju 


\section{Jurnal Manajemen Teori dan Terapan \\ Tahun 7. No. 2, Agustus 2014}

(CS) atau Cukup Sering (CS), Nilai 4 mewakili jawaban Setuju (S) atau Jarang (J) dan Nilai 5 mewakili jawaban Sangat Setuju (SS) atau Tidak Pernah (TP).

Pengumpulan data yang dilakukan dalam penelitian ini yaitu : (1.) Studi lapangan, yaitu memperoleh data primer dengan menyebarkan kuesioner kepada responden. Dalam hal ini respondennya yaitu karyawan PT. Panca Wana Indonesia, (2.) Studi kepustakaan, yaitu mempelajari literatur-literatur untuk menyusun landasan teori yang digunakan untuk menunjang dan berkaitan dengan permasalahan yang dihadapi untuk membantu permasalahan dalam penelitian ini.

Pada penelitian ini populasi yang digunakan adalah karyawan PT. Panca Wana Indonesia Indonesia di Krian yang berjumlah 612 karyawan. Menurut Winarsunu (2004) jika jumlah populasi kurang dari 10.000 maka penentuan besarnya sampel menggunakan rumus

slovin: $n=\frac{N}{1+N(e)^{2}}$ Keterangan: $n=$ Besarnya sampel, $N=$ Besarnya populasi, $e=$ tingkat kesalahan yang dapat ditolelir.

Dengan jumlah populasi dari karyawan PT. Panca Wana Indonesia sebanyak 612 dan tingkat kesalahan sebesar $10 \%$ yang didasarkan asumsi peneliti dan wawancara sumber perusahaan bahwa $90 \%$ dari jumlah populasi pernah mengalami atau terlibat baik secara langsung maupun tidak langsung dengan kecelakaan kerja, dan sebagian besar merupakan karyawan bagian produksi yang jumlahnya lebih dari $70 \%$ total karyawan secara keseluruhan. Maka jumlah sampel menurut rumus Slovin adalah 85,95 dibulatkan menjadi 86.

Penelitian ini menggunakan teknik Insidential Sampling, menurut Sekaran (2006) insidential sampling merupakan teknik penentuan sampel yang secara kebutulan ditemui oleh peneliti dan memenuhi kriteria. yaitu dalam penelitian ini kriterianya adalah supervisor dan karyawan pada bagian operasional dan produksi, dimana pada departemen tersebut sering terjadi kecelakaan kerja menurut sumber internal perusahaan.

\section{HASIL DAN PEMBAHASAN}

\section{Pengaruh Safety Climate terhadap Safety Behavior}

Dari hasil penelitian ini dapat diketahui bahwa safety climate berpengaruh secara signifikan terhadap kecelakaan kerja. Hipotesis ke-1 melihat pengaruh variabel safety climate terhadap kecelakaan kerja. Dari data pada tabel 4.16, menunjukkan bahwa safety climate berpengaruh signifikan terhadap kecelakaan kerja dikarenakan nilai signifikansi $\dagger$ sebesar 0,000 berada dibawah taraf signifikan sebesar 0,05. Oleh karena itu, hipotesis ke-1 dinyatakan diterima, bahwa variabel safety climate berpengaruh secara signifikan terhadap variabel kecelakaan kerja. 


\section{Mohammad Agus Setiawan \\ Tri Siwi Agustina}

Dilihat dari nilai mean dari variabel safety climate pada deskripsi jawaban responden dan berada pada kategori tinggi. Sedangkan untuk mean variabel kecelakaan kerja pada deskripsi jawaban responden berada pada kategori rendah. Hal tersebut menunjukkan bahwa karyawan PT. Panca Wana Indonesia mempunyai persepsi terhadap keselamatan kerja yang tinggi sehingga mengurangi tingkat kecelakaan kerja.

Hal ini ditunjukkan oleh adanya pengaruh negatif yang signifikan antara safety climate dengan kecelakaan kerja, sehingga apabila karyawan memiliki safety climate atau persepsi mengenai kebijakan, prosedur dan praktek keselamatan kerja maka akan semakin kecil kemungkinannya untuk terjadi kecelakaan kerja terhadap karyawan tersebut.

Hal tersebut sesuai dengan pernyataan Neal dan Griffin (2004) yang menjelaskan bahwa jika para karyawan secara individu mempunyai persepsi yang kuat terhadap terhadap perilaku manajer dan supervisi, kesadaran akan efektifitas sistem, tindakan yang mengarah pada resiko, tekanan pekerjaan, pengetahuan, kemampuan, dan kompetensi kerja. Maka persepsi yang kuat tersebut dapat meminimalkan terjadinya kecelakaan kerja.

Dilihat dari mean tiap indikator dalam variabel safety climate, nilai pada indikator 9 sampai dengan indikator 12 berada dalam kategori sedang dan rendah dimana keempat indikator tersebut merupakan indikator dari dimensi work pressure dalam variabel safety climate. Hal tersebut menunjukkan bahwa jadwal waktu, beban kerja, dan target kerja yang dirasakan karyawan PT. Panca Wana Indonesia dalam pelaksanaan pekerjaan dan aktivitas di tempat kerja dirasa kurang. Pernyataan tersebut mengindikasikan bahwa karyawan PT. Panca Wana Indonesia merasa cukup tertekan dengan tuntutan atau target pekerjaannya maupun beban kerja yang diberikan. Hal ini didukung dengan nilai mean pada indikator 3 dan 4 dari variabel kecelakaan kerja berada pada kategori sedang, dimana kedua indikator tersebut menunjukkan penyebab terjadinya kecelakaan kerja dikarenakan karyawan bekerja dengan kondisi stress dan terlalu lelah. Pernyataan tersebut mengindikasikan bahwa terjadinya kecelakaan kerja akibat stress dan beban kerja yang mengakibatkan kondisi lelah sering terjadi dibanding penyebab kecelakaan kerja lainnya dikarenakan beban kerja dan tekanan pekerjaan masih tinggi dirasakan oleh karyawan PT. Panca Wana Indonesia.

\section{Pengaruh Safety Climate terhadap Kecelakaan Kerja dengan Safety Behavior Sebagai Variabel Intervening}

Dari hasil penelitian ini kemudian diketahui bahwa safety climate berpengaruh secara signifikan terhadap kecelakaan kerja dengan safety behavior sebagai variabel intervening. Hipotesis ke-2 melihat pengaruh variabel safety climate terhadap kecelakaan kerja dengan safety behavior sebagai variabel intervening. Dari data pada tabel 4.16, 


\section{Jurnal Manajemen Teori dan Terapan \\ Tahun 7. No. 2, Agustus 2014}

menunjukkan bahwa safety climate berpengaruh signifikan terhadap safety behavior dikarenakan nilai signifikansi † sebesar 0,000 berada dibawah taraf signifikan sebesar 0,05, dan pada data tabel 4.13 nilai signifikansi t pada variabel safety behavior sebesar 0,000 dan berada dibawah taraf signifikan 0,05 . Hal ini menunjukkan bahwa safety climate mempunyai pengaruh langsung terhadap kecelakaan kerja dan pengaruh tidak langsung melalui safety behavior. Oleh karena itu hipotesis ke-2 dinyatakan diterima bahwa variabel safety climate berpengaruh secara signifikan terhadap variabel kecelakaan kerja dengan safety behavior sebagai variabel intervening.

Jika dilihat dari nilai mean dari variabel safety behavior pada deskripsi jawaban responden yaitu berada pada kategori sangat tinggi, sedangkan untuk mean variabel kecelakaan kerja berada pada kategori rendah. Hal tersebut menunjukkan bahwa perilaku keselamatan kerja karyawan PT. Panca Wana Indonesia sangat baik sehingga mengurangi terjadinya kecelakaan kerja. Perusahaan sangat baik dalam memperhatikan perilaku karyawan tentang keselamatan kerja, hal ini didukung dengan adanya safety climate yang baik, dimana dalam safety climate tentanf persepsi karyawan terhadap training yang diberikan terbukti berjalan baik sehingga perilaku karyawan menjadi lebih baik dalam hal keselamatan kerja. Karena terbukti jelas bahwa safety climate berpengaruh positif secara signifikan terhadap safety behavior, sehingga jika safety climate meningkat maka safety behavior juga akan meningkat.

Berdasarkan nilai mean dari indikator pada variabel safety behavior yang berada dalam kategori sedang adalah indikator yang berisi tentang pernyataan tidak menggunakan alat pelindung diri saat beraktivitas ditempat kerja, menunjukkan bahwa kesadaran karyawan dalam memakai alat pelindung diri masih berada dalam taraf cukup. Jika dibandingkan dengan indikator lain, maka indikator tersebut masih dibawah rata-rata variabel safety behavior. Perusahaan diharapkan benar-benar memperhatikan hal ini, dikarenakan tingkat perilaku keselamatan yang tinggi namun karyawan masih belum sadar akan pentingnya memakai alat pelindung diri saat beraktivitas sehingga akan menimbulkan terjadinya kecelakaan kerja. Dikarenakan safety behavior memiliki pengaruh positf yang signifikan terhadap kecelakaan kerja, maka kurangnya perhatian perusahaan dalam hal safety behavior karyawan khususnya dalam perilaku untuk menggunakan alat pelindung diri dapat menyebabkan terjadinya kecelakaan kerja.

Hasil temuan dalam penelitian ini didukung dengan temuan dari penelitian sebelumnya, salah satunya penelitian yang dilakukan Neal dan Griffin (2006) yang menemukan bahwa iklim keselamatan kerja (safety climate) menjadi prediktor dari kecelakaan, meskipun hubungan ini dijembatani oleh perilaku aman (safety behavior), dimana dalam safety climate terdapat dua aspek yaitu kebijakan organisatoris dan 


\section{Mohammad Agus Setiawan \\ Tri Siwi Agustina}

prosedur serta lingkungan kerja dan pelaksanaan. Selain itu Clarke (2006) juga menunjukkan adanya hubungan antara safety climate dengan unsafe behavior dimana unsafe behavior menjadi acuan untuk mengukur safety behavior, dan safety climate terhadap kecelakaan kerja.

\section{SIMPULAN}

Berdasarkan analisis dan pembahasan yang telah dilakukan, maka kesimpulan yang dapat diambil adalah sebagai berikut:

1. Hipotesis pertama yang menyatakan bahwa safety climate berpengaruh signifikan terhadap kecelakaan kerja pada karyawan PT. Panca Wana Indonesia terbukti, karena memiliki nilai signifikansi (Sig) † sebesar 0,000 lebih kecil dari nilai tingkat signifikansi (a) sebesar $5 \%(0,05)$.

2. Hipotesis kedua yang menyatakan bahwa safety climate mempunyai pengaruh tidak langsung dan signifikan terhadap kecelakaan kerja dengan safety behavior sebagai variabel intervening pada karyawan PT. Panca Wana Indonesia terbukti, karena nilai signifikansi (Sig) † variabel antara safety climate dengan safety behavior (XZ) sebesar 0,000 dan nilai signifikansi (Sig) † variabel antara safety behavior dengan kecelakaan kerja (ZY) sebesar 0,000 lebih kecil dari tingkat signifikansi a sebesar $5 \%$ $(0,05)$.

\section{SARAN}

Sebagai implikasi dari hasil penelitian ini dapat dikemukakan beberapa saran yang dapat dipertimbangkan atau dimanfaatkan sebagai bahan dalam pengambilan keputusan, antara lain:

1. Sebaiknya pihak manajemen PT. Panca Wana Indonesia tetap mempertahankan kinerjanya dalam hal safety climate terutama dalam aspek dukungan sistem manajemen informasi dalam hal pengumpulan dan penyampaian informasi yang berkaitan dengan keselamatan kerja, dan ketersediaan prosedur kerja secara jelas dan lengkap untuk pekerja dalam aktivitasnya di tempat kerja.

2. Dikarenakan jawaban yang diberikan responden untuk perilaku keselamatan kerja pada karyawan PT. Panca Wana Indonesia berada pada kategori sangat tinggi. Maka sebaiknya pihak manajemen PT. Panca Wana Indonesia harus mempertahankan perilaku keselamatan yang sudah sangat baik, agar tidak 


\section{Jurnal Manajemen Teori dan Terapan \\ Tahun 7. No. 2, Agustus 2014}

terjadi kecelakaan kerja yang diakibatkan oleh perilaku karyawan yang tidak mementingkan keselamatan saat bekerja.

\section{REFERENSI}

Pekerja Terhadap Keselamatan Kerja (Online). (http://dewey.petra.ac.id. Diakses 2 September 2014) Surabaya. Universitas Kristen Petra.

Christian, M.S. et al,. 2009. Workplace Safety: A Meta-Analysis of the Roles of Person and Situation Factors. Journal of Applied Psychology, Vol: 94 (5). 1103-1127.

Clarke, S. 2006. Safety Climate in an Automobile Manufacturing Plant: the Effect of Work Environment, Job Communication and Safety Attitudes on Accident and Unsafe Behaviour. Personnel Review, 35. 413-430.

Cooper, M.D., 2000. Towards a Model of Safety Culture. Safety Science, 36 (2). 111-136.

2009. Behavioral Safety Interventions: A Review of Process Design Factors. Safety Management. 36-45.

Cooper, M.D. \& Phillips, R.A., 2004. Exploratory Analysis of the Safety Climate and Safety Behavior Relationship. Journal of Safety Research: 35. 497-512.

DeJoy, D. et al., 2004. Creating Safer Workplace: Assesing the Determinants and Role of Safety Climate. Journal of Safety Research, 35. 81-90.

Flin, R. et al., 2000. Measuring Safety Climate: Identifying the Common Features. Safety Science, 34. 177-192.

Fogarty, G.J., Shaw, A., 2010. Safety Climate and the Theory of Planned Behavior: Towards the Prediction of Unsafe Behavior. International Journal of Applied Aviation Studies, 42. 1455-1459.

Glendon, A.I. \& Litherland, D.K. 2001. Safety Climate Factors, Group Differences and Safety Behavior in Road Construction. Safety Science, Vol. 33. 33-51.

Guldenmund, F. 2000. The Nature of Safety Culture: A Review of Theory and Research. Safety Science, 34 (1-3). 215-257.

Hayes, B.E. et al,. 1998. Measuring Perceptions of Workplace Safety: Development and Validation of the Work Safety Scale. Journal of Safety Research, 29. 145-161.

Hofmann, D.A., \& Stetzer, A. 1996. A Cross-level Investigation of Factors Influencing Unsafe Behavior and Accidents. Personnel Psychology, 49. 307-339.

Lisnandhita, Yudithia. 2012. Pengaruh Kepemimpinan, Budaya Keselamatan Kerja, dan IKlim Keselamatan Kerja Terhadap Perilaku Keselamatan Kerja: Studi Kasus di PT. Krama Yudha Ratu Motor. Skripsi tidak diterbitkan. Jakarta. Fakultas Ekonomi Universitas Indonesia.

Martinez-Corcoles, Mario., Gracia, Francisco., M.Piero, Jose. 2011. Leadership and Employees' Perceived Safety Behaviours in a Nuclear Power Plant: A Structural Equation Model. Safety Science Vol. 49, 1118-1129.

Neal, Andrew \& Griffin Mark A., 2000. Perceptions of Safety at Work: A Framework for Linking Safety Climate to Safety Performance, Knowledge, and Motivation. Journal of Occupational Health Psychology Vol 5 No. 3, 347-358. 
Mohammad Agus Setiawan

Tri Siwi Agustina

Patria, Bhina. 2007. Bagaimana Behavioral Safety Mengurangi Angka Kecelakaan Kerja (Online), (http://inparametric.com/bhinablog, diakses 12 Agustus 2014).

Reason, J., 1997. Human Error: Models and Management. British Medical Journal, 320. 768770.

Robbins, Stephen.P., \& Jusge, Timothy A. 2008. Perilaku Organisasi edisi 12. Terjemahan oleh Diana Angelica. Jakarta: Salemba Empat.

Setiawan, Mohammada Agus dan Tri Siwi Agustina, 2015. Pengaruh Safety Climate Terhadap Kecelakaan Kerja Dengan Safety Behavior Sebagai Variabel Intervening Pada Karyawan PT. PANCA WANA INDONESIA, Program Studi S1 Manajemen Fakultas Ekonomi dan Bisnis Universitas Airlangga, 124.

Sekaran, Uma. 2006. Metodologi Penelitian. Jakarta: Gramedia.

Sugiyono. 2007. Metode Penelitian Bisnis. Bandung: Alfabeta.

Wicaksono, A.A. 2005. Hubungan Antara Safety Climate Dengan Safety Performance. Skripsi tidak diterbitkan. Surabaya. Fakultas Psikologi Universitas Surabaya.

Zhou, et al. 2007. A Methode to Identify Strategies for the Improvement of Human Safety Behavior by Considering Safety Climate and Personal Experience. Safety Science, 46 (2008). 1406-1419.

http://www.depnakertrans.go.id/perundangan.html,1,168,7 